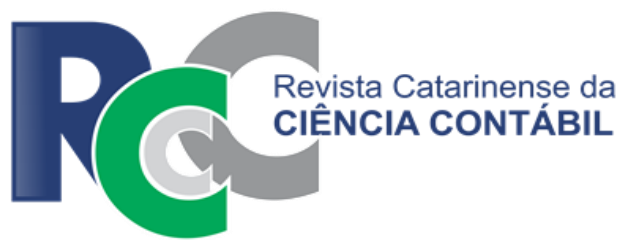

\title{
PRESTAÇÃO DE CONTAS DE PROJETOS DE PESQUISA: UMA ANÁLISE DOS RELATÓRIOS E DOS CONTROLES INTERNOS EM UMA FUNDAÇÃO DE APOIO NO BRASIL
}

\author{
ACCOUNTABILITY OF RESEARCH PROJECTS: AN ANALYSIS OF REPORTS \\ AND INTERNAL CONTROLS IN A SUPPORT FOUNDATION IN BRAZIL
}

\author{
RODRIGO DE SOUZA GONÇALVES \\ Universidade de Brasília. Endereço: Campus Universitário Darcy Ribeiro, \\ Prédio da FACE | Asa Norte | 70910-900| Brasília/DF | Brasil. \\ Dhttp://orcid.org/0000-0003-3768-2968 \\ rgoncalves@unb.br
}

\author{
ANDRÉA DE OLIVEIRA GONÇALVES \\ Universidade de Brasília. Endereço: Campus Universitário Darcy Ribeiro, \\ Prédio da FACE | Asa Norte | 70910-900 | Brasília/DF | Brasil. \\ (D)http://orcid.org/0000-0001-7514-8139 \\ andreagon@unb.br
}

\author{
ÁLVARO BRAGANÇA MARQUES \\ Universidade de Brasília. Endereço: Campus Universitário Darcy Ribeiro, \\ Prédio da FACE | Asa Norte | 70910-900| Brasília/DF | Brasil. \\ (1) http://orcid.org/0000-0003-4782-4384 \\ alvarob.braganca@gmail.com
}

\section{LUCAS BARCELOS GORDO}

Universidade de Brasília. Endereço: Campus Universitário Darcy Ribeiro, Prédio da FACE | Asa Norte | 70910-900| Brasília/DF | Brasil. (1) http://orcid.org/0000-0002-5836-1947

lucasbgordo17@gmail.com

\section{RESUMO}

Este artigo analisa se os relatórios de prestação de contas dos projetos de pesquisa financiados pela FAPDF, Brasil, atendem os requisitos legais. Para tanto foram analisados 116 relatórios de prestação de contas relativos aos editais de fomento do período de 2008 a 2010. Para melhor compreensão das evidências obtidas pela etapa anterior, foram realizadas entrevistas com pesquisadores beneficiados pelos editais, cujos dados foram analisados por meio de estatística descritiva e princípios de análise de conteúdo. Os resultados obtidos pela análise dos relatórios de prestação de contas apontam a existência, com maior frequência e persistência de ressalvas oriundas de: 1) utilização de rendimentos financeiros sem autorização $(34,5 \%)$; 2) não apresentação dos três orçamentos para os itens de capital $(23,3 \%) ; 3)$ não apresentação de todos extratos bancários; e 4) não utilização de cheque nominativo para pagamento de despesas $(33,6 \%)$. Os resultados das entrevistas corroboram que tais evidências são impulsionadas pela ausência de clareza e Artigo apresentado no $3^{\circ}$ Congresso UnB de Contabilidade e Governança, de 29 de novembro a 1 de dezembro de 2017 em Brasília/DF. 
dificuldade de entendimento às regras estabelecidas pelos editais de fomento. Para tanto, concluise quanto à necessidade de adoção de mecanismos de controle que monitorem o uso dos recursos públicos, bem como o mapeamento das ocorrências de ressalvas nos relatórios de prestação de contas.

Palavras-chave: Prestação de Contas. Fundação de Apoio à Pesquisa. Recursos Públicos. Controle Interno.

\begin{abstract}
This article analyzes whether the accountability reports of research projects financed by FAPDF (Research Support Foundation for Distrito Federal), Brazil, meets the legal requirements. To this end, 116 accountability reports related to application guidelines for the period of 2008 to 2010 were analyzed. For a better understanding of the evidence obtained by the previous stage, interviews were conducted with researchers benefiting from the application guidelines, whose data were analyzed through descriptive statistics and principles of content analysis. The results obtained by the analysis of the accountability reports show the existence, more frequently and persistently, of reservations arising from: 1) the use of financial income without authorization (34.5\%);2) non-presentation of the three budgets for capital items (23.3\%); 3) non-presentation of all bank statements; and 4) non-use of nominative check for payment of expenses (33.6\%). The results of the interviews corroborate that such evidences are driven by the lack of clarity and difficulty of understanding the established rules by the application guidelines. To do so, it is concluded that there is a need to adopt control mechanisms that monitor the use of public resources, as well as the mapping of occurrences of reservations in accountability reports.
\end{abstract}

Keywords: Accountability. Research Support Foundation. Public Resources. Internal Control.

\title{
1 INTRODUÇÃO
}

Nos últimos anos, a administração pública passou por diversas transformações, destacando-se, entre elas, o esforço da migração do modelo burocrático para o gerencial, voltado não apenas a aspectos formalísticos, mas também na busca de resultados que agreguem maior valor aos serviços disponibilizados ao cidadão.

No contexto de produção de conhecimento e inovação que busquem melhorias no setor público, tem-se as entidades de fomento, a exemplo das fundações de apoio à pesquisa. No Distrito Federal encontra-se a Fundação de Apoio à Pesquisa do Distrito Federal (FAPDF), fundação pública que tem por finalidade "estimular, apoiar e promover o desenvolvimento científico, tecnológico e de inovação do Distrito Federal, visando ao bem-estar da população, defesa do meio ambiente e progresso da ciência e tecnologia" (FAPDF, 2017).

A produção científica na busca de inovação e melhorias à sociedade tem merecido especial atenção, pois a partir de 2013 uma alteração na Lei Orgânica do Distrito Federal (1993) passou a destinar mensalmente o mínimo de $2 \%$ da Receita Orçamentária do Governo do Distrito Federal à FAPDF, os quais devem ser aplicados no desenvolvimento científico e tecnológico. Ocorre que, para o bom uso dos recursos aplicados em pesquisa científica e tecnológica, é necessário adotar um conjunto de medidas e métodos adaptados para o cumprimento de suas obrigações e processos gerenciais nas respectivas fundações de apoio.

Nesse cenário lança-se luz ao papel desempenhado pelos controles internos, que têm entre os seus objetivos o de salvaguardar os recursos, garantir a confiabilidade e correção das operações e da informação, estimular a adesão às políticas e normas estabelecidas, e que as organizações 
cumprirão suas obrigações de accountability de modo a alcançar a sua missão (Resolução CFC n ${ }^{\circ}$ 1.135 de 2008 (2008); INTOSAI, 2004).

Segundo a Resolução CFC no 1.135 (2008), em seu item 2, os controles internos, em especial no setor público, devem atentar-se para a observação de diversos aspectos, sendo eles: “(a) salvaguardar os ativos e assegurar a veracidade dos componentes patrimoniais; (b) dar conformidade ao registro contábil em relação ao ato correspondente; (c) propiciar a obtenção de informação oportuna e adequada; (d) estimular adesão às normas e às diretrizes fixadas; (e) contribuir para a promoção da eficiência operacional da entidade; (f) auxiliar na prevenção de práticas ineficientes e antieconômicas, erros, fraudes, malversação, abusos, desvios e outras inadequações".

A esse respeito, Capovilla (2016, p. 18) afirma que "os gestores públicos têm sido estimulados a implantar estruturas de controle interno eficazes, que contribuam para diminuir o risco de que as organizações governamentais sejam administradas em desacordo com os interesses dos cidadãos". Para tanto, espera-se que as entidades públicas disponham de mecanismos de auditoria, tanto interno como externo, com objetivo de que suas estruturas de controle interno possam servir de apoio às ações do gestor público na busca da correta alocação dos recursos públicos.

Tendo em vista o aspecto sistêmico das auditorias, esta deve servir de instrumento de auxílio ao gestor na medida em que busca, dentre outros aspectos, segundo Capovilla (2016, p. 20) "obter entendimento adequado da eficácia dos controles internos da entidade", que por sua vez, permitirá aferir a confiabilidade e a validação dos procedimentos internos adotados pelas organizações, neste caso, acerca do uso dos recursos aplicados nos projetos de pesquisa.

Sob esse prisma, espera-se que à medida que são adotados controles internos para monitoramento da execução orçamentária dos projetos de pesquisa, seja possível realizar um acompanhamento que permita que a alocação dos recursos se dê em conformidade com os requisitos legais e editalícios. Para tanto tem-se a seguinte questão de pesquisa: em que medida o sistema de controles internos da FAPDF contribui no acompanhamento e análise da conformidade da alocação de recursos financeiros dos projetos de pesquisas em que financia?

Considerando tais aspectos, este artigo objetiva analisar o sistema de controles internos da FAPDF vis a vis a conformidade da prestação de contas dos projetos de pesquisas financiados com vistas ao cumprimento de seu objetivo institucional. Como objetivos específicos tem-se: 1) avaliar os relatórios de prestação de contas a partir do arcabouço legal que os projetos de pesquisas estão submetidos; e 2) identificar a percepção dos pesquisadores contemplados com recursos em seus projetos, acerca dos procedimentos realizados para execução do cronograma financeiro e sua prestação de contas.

O artigo tem sua sustentação teórica nos conceitos de accountability, prestação de contas e auditoria - este último centrado no papel do sistema de controles internos. Conceitos estes que no âmbito da administração pública estão associados à responsabilidade, à obrigação em prestar contas segundo os parâmetros da lei, que envolve a possibilidade de ônus ou a pena para o não cumprimento dessa diretiva. Para tanto, esta pesquisa avança ao buscar compreender o processo de prestação de contas ao qual o responsável pela execução do recurso deve se submeter, seus desafios e dificuldades para o cumprimento dessa tarefa.

Por outro lado, busca-se também identificar os desafios vivenciados pela FAPDF, à medida que esta deveria dispor de mecanismos de controle a fim de monitorar e avaliar os relatórios de prestação de contas, e ainda, promover ações que busquem alinhar os interesses da sociedade e da comunidade científica, não somente no que tange aos resultados das pesquisas financiadas, mas inclusive em relação à correta alocação dos recursos destinados aos respectivos projetos.

O percurso metodológico do artigo está voltado para uma orientação descritiva, com olhar qualitativo, debruçado sobre os relatórios de prestação de contas entregues do período entre 2011 a 2016, bem como a percepção dos pesquisadores beneficiados. 


\section{REFERENCIAL TEÓRICO}

\section{Accountability, Prestação de Contas e Auditoria}

A definição do termo accountability é de complexa tradução, havendo divergências sobre a real expressão do termo na língua portuguesa. Porém, a ideia básica abrange a avaliação e responsabilização daqueles que foram confiados recursos ou poderes. O`Donnell (1998) classifica a accountability na sociedade em vertical e horizontal, a primeira sendo a escolha de líderes, no meio democrático, como forma de premiação ou sanção de atos praticados por um ou um grupo, e a segunda, como forma de fiscalização entre poderes, conhecida como sistema de checks and balances (ou pesos e contrapesos). Na visão vertical, existe a relação entre sociedade e Estado, enquanto na horizontal, essa relação se dá entre os representantes do próprio Estado. Assim sendo, é por meio da accountability horizontal em que é exercida a fiscalização institucional entre entes públicos, supervisionando, avaliando e punindo, caso necessário, os agentes ou órgãos responsáveis, conforme parâmetros pré-estabelecidos.

Rocha (2011) explica que a accountability pode ser entendida como processo de avaliação e responsabilização dos agentes públicos, seja diretamente perante a sociedade ou perante órgãos fiscalizadores internos por ações ou omissões, podendo sofrer sanções, seja de ordem legal ou moral. Segundo Campos (1990), a preocupação em ter conhecimento daquilo que se foi feito com o recurso público é um bom item para inferir o amadurecimento da sociedade. E, por esta e outras interpretações, a accountability se torna um vocábulo em constante uso na administração pública voltada para eficiência e economicidade.

Todavia, Lopes e Freire (2010, p. 72 ) problematizam em torno do conceito de accountability ao dizer que "não se pode limitar tal conceito entorno apenas em prestar contas quanto aos seus aspectos quantitativos, mas de auto avaliar a obra feita, de dar a conhecer o que se conseguiu e de justificar aquilo em que se falhou".

No caso brasileiro, a Constituição Federal de 1988, em seu artigo 70, parágrafo único, dá ordem legal sobre o tema, contemplando o sentido estrito de accountability, porém, expandindo a responsabilização e avaliação a todos aqueles que utilizarem recursos públicos: "prestará contas qualquer pessoa física ou entidade pública que utilize, arrecade, guarde, gerencie ou administre dinheiros, bens e valores públicos ou pelos quais a União responda, ou que, em nome desta, assuma obrigações de natureza pecuniária".

É indiscutível, portanto, a importância do termo accountability uma vez que a sociedade demanda por informações sobre o que foi feito, por que foi feito, por quanto, como e demais esclarecimentos a respeito do recurso público gasto. É importante que o serviço público desempenhe este papel, de modo eficiente e eficaz perante a sociedade, a fim de atender a demanda da população.

Desta forma, o termo accountability no âmbito da administração pública no Brasil passa a se tornar, portanto, um discurso constante, haja vista que a partir dos anos 1995, instala-se no Brasil o novo processo de Reforma do Aparelho do Estado. Esse processo foi materializado pelo Plano Diretor e seu objetivo era transformar a administração pública brasileira em um serviço profissional baseado no Estado de direito e na competência técnica, tornando assim, o aparelho do Estado mais efetivo (Bresser-Pereira, 2002). De acordo com a literatura internacional, amplamente debatida, é na terceira fase do New Public Management - "Public Service Orientation" (Denhardt, 2012), que seu eixo central passa a ser a accountability e a equidade. Baseia-se em princípios republicanos e democráticos e prega valores como transparência, participação política e justiça, temas até então ausentes do debate sobre o modelo gerencial.

No caso brasileiro, o texto constitucional que trata da relação entre Estado e sociedade recomenda o envolvimento direto da sociedade por meio da participação nos conselhos de administração dos diversos segmentos representativos da sociedade civil (Bresser-Pereira, 1997, p. 14), com o objetivo maior de reivindicar o melhor desempenho, a qualidade e a efetividade dos serviços prestados à população. Assim, o novo modelo de gestão pública gerencial envolveu a 
descentralização da execução de políticas sociais - - ações de caráter local e de infraestrutura com previsão de acompanhamento dos gastos pela sociedade, bem como propôs a descentralização da execução de políticas públicas para outros entes da federação; a desconcentração da execução dessas políticas da União para outros órgãos da mesma esfera federal; e a publicização compreendida aqui como a descentralização para organizações sociais (Bresser-Pereira, 1997).

A partir daquele momento inúmeras ações foram implementadas. Inclui-se aí a crescente autonomia e accountability dos tomadores de recursos públicos, que são provocados a produzir os relatórios de prestação de contas cada vez mais claros e objetivos. Neste sentido, a informação na prestação de contas deve conter características inerentes como a tempestividade, materialidade, relevância, confiabilidade, neutralidade, para que a mesma seja útil, não somente para o processo decisório, mas inclusive como subsídio da avaliação das ações dos gestores no sentido de fazer com que os aspectos relativos ao processo de accountability ocorram.

A informação, porém, quando mal utilizada poderá ser tendenciosa e enviesada de forma a corroborar ações que o gestor realizou, mas não deseja evidenciar face ao prejuízo pessoal que esta poderá causar. Segundo Gonçalves, Gonçalves e Tavares (2011, p. 663), "no que concerne ao escopo das informações divulgadas, Hendriksen e Van Breda (1999) e Scott (1941) entendem que toda informação deve atender aos princípios de justiça, equidade e verdade de forma a contribuir com o aumento do bem-estar de todos. Quanto ao aumento do bem-estar vale ressaltar a observância do aprimoramento dos princípios de governança que não contempla somente a prestação de contas, mas também a equidade". Ela se faz necessária, principalmente no contexto deste estudo, tendo em vista seu aspecto sistêmico, especialmente no que tange ao sistema de controles internos que deve assegurar que as ações sejam convergentes para o cumprimento dos objetivos estratégicos da organização (COSO, 2013).

Nesse sentido, a Federação Internacional de Contadores (IFAC, 2001) define quatro dimensões para nortear as práticas de governança no setor público: 1) padrões e comportamentos; 2) estrutura organizacional e processos, cujo foco está na transparência e responsabilização das partes envolvidas; 3) estrutura de controles - com objetivo de se alcançar nas organizações controle interno efetivo, auditoria interna autônoma e capacitação dos funcionários para a compreensão da responsabilidade pela mitigação do risco organizacional; e 4) relatórios de gestão - cujo objetivo é, dentre outros elementos, atrelar o compliance dos dados informados e avaliação de desempenho.

Quanto à relação entre a qualidade dos controles internos e a fidedignidade das informações prestadas, o Committee on the Financial Aspects of Corporate Governance (1992) enfatiza que tais elementos somente são alcançados à medida que há espaço adequado para o profissionalismo de seus integrantes, indo ao encontro do que preconiza o IFAC (2001). Não menos importante, na visão de Schwartz, Dunfee e Kline (2005), para que tais mecanismos tenham efetividade há o necessário comprometimento da alta administração, conhecido pela expressão "tone at the top".

Desse modo, para Bergamini (2005, p. 158), a materialização dos riscos operacionais "ocorrem em função de desenho organizacional inadequado, da falta de planejamento e de monitoração na delegação de poderes, da utilização de procedimentos sem uniformidade e da obsolescência de produtos e processos". Portanto, a estrutura de governança corporativa deve manter um gerenciamento de riscos de maneira integrada, com controles internos efetivos patrocinada pela alta administração (Zahra, 2014; Schwartz, Dunfee, \& Kline, 2005).

Assim sendo, questões centrais como: o que, onde, como e quanto no que concerne à tomada de decisão na alocação, supervisão e monitoramento dos recursos, poderão ser melhor definidas, o que contribuirá para o papel a ser exercido pela auditoria e dos controles internos na revisão dos procedimentos de alocação de recursos e sua prestação de contas.

Lima e Castro (2006) afirmam que a auditoria deve atuar no auxílio ao administrador na tomada de decisões, por meio de relatórios e pareceres; bem como, na evidenciação de erro, omissão ou fraude, com vistas salvaguardar o patrimônio da entidade.

Já Castro (2008, p. 86) argumenta que "a auditoria precisa atuar validando e dando 
credibilidade aos dados divulgados, tornando-se responsável por controlar a qualidade dos mesmos. Aí está o papel do controle interno e da auditoria".

Assim, por meio de uma auditoria atuante é possível identificar falhas, processos e apontar soluções no campo da gestão das organizações. Observa-se que, no caso das Fundações de Apoio à Pesquisa, estas devem possuir e atender aos dois tipos de auditoria existentes, a auditoria interna e a auditoria externa.

A auditoria externa, que nos entes públicos é exercida pelos Tribunais de Contas, é focada em emitir opinião sobre os relatórios financeiros, no caso, acerca dos relatórios de prestação de contas dos projetos de pesquisa.

Já a auditoria interna deve voltar-se no auxílio à administração para que esta cumpra seus objetivos, por meio da avaliação dos processos, sistemas e controles internos (Fontenelle \& Brito, 2013; Silva, 2009; Vieira \& Freitas, 2015). Nesta perspectiva, observa-se que a auditoria interna deve entender a estrutura e cultura organizacional, a legislação aplicável e normatização interna para melhor desempenhar seu trabalho. Apenas assim pode alcançar seu objetivo e contribuir para o alcance dos objetivos estratégicos da organização.

Tais aspectos afetam o controle interno e a forma que a organização responde a situaçõesproblema identificadas nas organizações. Desta forma, a auditoria vai além da conferência dos registros contábeis, averiguando também processos operacionais e podendo fazer uma análise com limite temporal maior que a auditoria externa (Ferreira, 2002).

\section{METODOLOGIA}

Este estudo tem por objeto os relatórios financeiros de prestações de contas dos projetos de pesquisa científica e tecnológica fomentados pela FAPDF e os documentos que dão suporte ao processo de prestação de contas. Assim, trata-se de uma pesquisa descritiva, com procedimentos técnicos documentais, utilizando dados primários sem tratamento analítico (Hair, Rabin, Money, \& Samouel, 2005).

\subsection{Lócus da Pesquisa}

A FAPDF foi criada pela Lei Distrital nº 347 de 1992 e entrou em funcionamento em 1993. Ela é fundação pública, com personalidade jurídica de direito privado, que tem por finalidade apoiar, promover e estimular o desenvolvimento científico e tecnológico e da inovação do Distrito Federal (FAPDF, 2017).

Oliveira, Hochman, Nahas e Ferreira (2005) discorrem que a pesquisa científica apoia o desenvolvimento acadêmico, surtindo grandes efeitos principalmente entre graduandos e pósgraduandos. Porém, é necessário apoio financeiro para promover estas pesquisas. Assim, as agências de fomento são de grande importância também para o desenvolvimento universitário. As Fundações de Apoio à Pesquisa (FAP), vinculadas aos estados e Distrito Federal, atuam por meio de editais, por área específica ou demanda espontânea dos pesquisadores, oferecendo suporte às propostas de pesquisa por meio de bolsas, auxílios para participação e promoção de eventos científicos, aquisição de materiais, entre outros auxílios que são necessários ao desenvolvimento da pesquisa.

Segundo seu Estatuto Social (Decreto distritral no 27.958, 2007) e alterações, a FAPDF é composta por dois órgãos colegiados, o Conselho Superior e o Conselho Diretor. O primeiro é órgão deliberativo que é constituído pelo Diretor-Presidente e quatorze outros membros. O segundo é incumbido da gestão técnico-científica e administrativa da Fundação, formado pela Presidência, pela Superintendência Científica, Tecnológica e de Inovação, e por fim pela Superintendência da Unidade de Administração Geral. Existem ainda as Câmaras de assessoramento que são constituídas por pessoas de notório conhecimento da área científica e competem elaborar programas e editais, e ainda analisar e recomendar os pedidos de apoio a 
projetos ao Conselho Diretor e emitir pareceres e relatórios de avaliação e controle dos projetos científicos.

\subsection{Coleta de dados e Análise dos Dados}

Os dados foram coletados nos relatórios financeiros de prestação de contas dos projetos de pesquisa científica e tecnológica sem ainda terem sido submetidos à análise interna da FAPDF. Considerando o momento em que os dados foram coletados, delimitou-se para identificação dos relatórios a serem analisados, aqueles que possuíam como prazo prescricional dia 31 de maio de 2016. Conforme Instrução Normativa 01 (2005), da Corregedoria-Geral do Distrito Federal, os órgãos de controle interno e externo podem tomar medidas em até cinco anos do prazo de entrega do relatório de prestação de contas.

Assim, o prazo para análise das prestações foi fixado entre 1 de junho de 2011 a 31 de maio de 2016. Como os projetos de pesquisa duram, conforme edital, dois anos e são renováveis por igual período, seria possível projetos de pesquisa de editais de 2008 terem prestado contas em 2011. Portanto, os editais analisados foram aqueles com publicação entre 2008 e 2016, com prestação de contas entre 1 de junho de 2011 a 31 de maio de 2016.

Para definição da quantidade dos relatórios, levantou-se dados sobre 77 editais entre 2008 e 2016, disponibilizados no site da FAPDF à época da coleta. Importa destacar que esse procedimento foi realizado em razão da ausência de controles internos que apontassem os referidos editais bem como os projetos aprovados e executados. De início, esse aspecto salta aos olhos, à medida que vai contra ao que se espera de um sistema de controle que propicie segurança razoável quanto à realização de procedimentos internos que estejam alinhados aos objetivos organizacionais, conforme propõem os principais frameworks de controles internos (COSO, 2013; GAO, 2001).

A ausência completa de um sistema de controles conforme, inicialmente identificado, normalmente ocorre quando não há um aspecto básico para a existência desse componente: o apoio dos principais dirigentes da organização - o tone at the top (Schwartz, Dunfee, \& Kline, 2005; COSO, 2013). Superado essa questão, pode-se tomar como ponto de partida os componentes do COSO (2013) a fim de elaborar uma estrutura de controles internos, e, com o auxílio de um modelo de maturidade, a exemplo do que propõem Capovilla, Gonçalves, Dantas e Oliveira (2018), identificar as características necessárias para a implantação dessa estrutura, bem como os avanços necessários para que ela contribua com o alcance dos objetivos organizacionais.

Do total de 77 editais identificados, 15 destinavam-se ao apoio aos projetos de pesquisa, foco em análise da pesquisa. Contudo, excluíram-se 5 editais, sendo: 1) 1 encontrava-se ainda em fase de andamento de pesquisa; 2) 1 cancelado por corte orçamentário, 3) 1 não obteve proposta aprovada; e 4) 2 editais cujos projetos e relatórios financeiros não foram disponibilizados pela FAPDF. Assim, foram analisados os processos constantes em dez editais contidos entre os anos de 2008 a 2010. Deles, foram identificados os processos que continham relatório de prestação de contas financeiras entregues no corte temporal delimitado, obtendo-se um universo de 152 processos de prestação de contas financeiras. À medida que os processos eram entregues para análise, foram descartados um total de 36 processos, sendo: 1) 4 processos arquivados; 2) 16 com ausência de prestação de contas; 3) 10 por não terem sido disponibilizados; e 4) 6 com prestação de contas já analisadas pela FAPDF. Portanto, foi analisado um total de 116 processos e seus respectivos relatórios financeiros.

Após a análise dos relatórios, e com objetivo de aprofundar o conhecimento do objeto de estudo, foi elaborado um questionário e destinado aos 113 pesquisadores que submeteram as prestações de contas dos processos no período analisado. O questionário aos pesquisadores foi construído com base no instrumento de pesquisa desenvolvido para análise dos relatórios de prestação de contas (detalhes no item 3.3), com doze questões fechadas, com padrão de resposta de acordo com escala do tipo Likert, e uma questão aberta, para obter sugestões dos pesquisadores. As questões foram distribuídas em duas seções, relacionadas: 1) em que frequência o pesquisador 
observava as normas cabíveis para a realização das despesas do projeto de pesquisa; e 2) quanto ao nível de dificuldade ao efetuar a prestação de contas. Para a primeira seção, o padrão utilizado foi uma escala entre nunca, raramente, às vezes, muitas vezes e sempre; e na segunda seção foi utilizada uma escala entre nenhuma, muito pouca, pouca, média e muita.

Os questionários foram disponibilizados por e-mail e a taxa de respostas alcançou 34,51\%, ou seja, 39 respondentes. Os dados do questionário foram analisados por meio da estatística descritiva e seus resultados foram confrontados com os resultados dos relatórios de prestação de contas.

\subsection{Instrumento de Análise dos Relatórios}

A pesquisa realizada possuiu um plano de auditoria, com cronograma, competências, objetos, objetivos e justificativas. Para tanto o programa de auditoria elaborado dispunha de procedimentos para cumprir objetivos, delimitações e efetuação de exames (Silva, 2009).

Para aplicação dos procedimentos previstos e suportar a opinião final sobre a aderência dos relatórios ao respectivo edital, foi utilizada a técnica de análise documental, por meio de instrumento de pesquisa que avaliou a conformidade dos relatórios de prestação de contas com seu respectivo edital. A análise dos relatórios foi feita a partir do arcabouço teórico deste estudo, bem como a conformidade dos procedimentos para execução orçamentária a partir da legislação aplicável.

O instrumento de pesquisa foi desenvolvido na forma de checklist e avaliou dez itens considerados relevantes que o pesquisador deve comprovar, a fim de considerar sua prestação de contas de acordo com seu respectivo edital e a legislação. As variáveis do instrumento de pesquisa e seu embasamento legal encontram-se na Tabela 1.

Tabela 1

\section{Embasamento legal do checklist}

\begin{tabular}{|c|c|}
\hline Varáveis & Sustentação Legal \\
\hline Gastos estavam previstos no orçamento? & Instrução Normativa 01 , art. $8^{\circ}$, IV \\
\hline Apresentou documentos comprobatórios dos gastos? & Instrução Normativa 01 , art. $28^{\circ}$ \\
\hline Apresentou três orçamentos das aquisições? & Lei $\mathrm{n}^{\circ} 8.666 / 1993$, art. $15^{\circ}$ \\
\hline $\begin{array}{l}\text { Quando autorizado, os gastos com diária foram menores que o } \\
\text { máximo permitido? }\end{array}$ & $\begin{array}{l}\text { Resolução Normativa, 01, de } 16 \text { de } \\
\text { agosto de } 2013\end{array}$ \\
\hline $\begin{array}{l}\text { Houve remanejamento de recursos destinados de rubrica para } \\
\text { outra rubrica? }\end{array}$ & Lei $n^{\circ} 4,320 / 1964$, art. $11^{\circ}$ \\
\hline $\begin{array}{l}\text { Houve remanejamento de recursos destinados a elemento de } \\
\text { despesa para outra, na mesma rubrica, acima de } 20 \% \text { ? }\end{array}$ & Termo de Outorga e Aceitação (TOA) \\
\hline Utilizou rendimentos financeiros sem autorização da FAPDF? & Instrução Normativa 01, art. $7^{\circ}$, XIV \\
\hline Devolveu o valor residual? & Instrução Normativa 01, art. $7^{\circ}, \mathrm{XI}$ \\
\hline Apresentou todos os extratos bancários da conta? & Instrução Normativa 01 , art. $7^{\circ}$, VII \\
\hline $\begin{array}{l}\text { Utilizou cheque nominativo, quando obrigatório, para } \\
\text { pagamento de despesa? }\end{array}$ & Termo de Outorga e Aceitação (TOA) \\
\hline
\end{tabular}

Fonte: Dados da pesquisa (2017)

Para cada relatório analisado foi elaborada uma sugestão de parecer. Cada relatório foi classificado em: "sem ressalvas", quando estava em conformidade com edital e legislação aplicável, e "com ressalvas" quando identificou-se no relatório algum item em desconformidade com edital e legislação vigente. 


\section{ANÁLISE DOS RESULTADOS}

Foram examinados 116 processos, com seu respectivo relatório financeiro, distribuídos em dez editais no período de 2008 a 2010. Importa destacar que dos anos de 2011 a 2016 não foram analisados relatórios em razão de no ano de 2011 não ter ocorrido a publicação de editais e, os dos anos de 2012 a 2016 por se tratarem de projetos que se encontravam em andamento, e portanto, não dispunham, no momento da execução da pesquisa, dos relatórios de prestação de contas.

Considerando-se dessa forma o período analisado (2008-2010), foi possível identificar, a partir dos relatórios de prestação de contas, a seguinte tendência acerca da ocorrência de ressalvas ou não por edital, conforme a Figura 1.

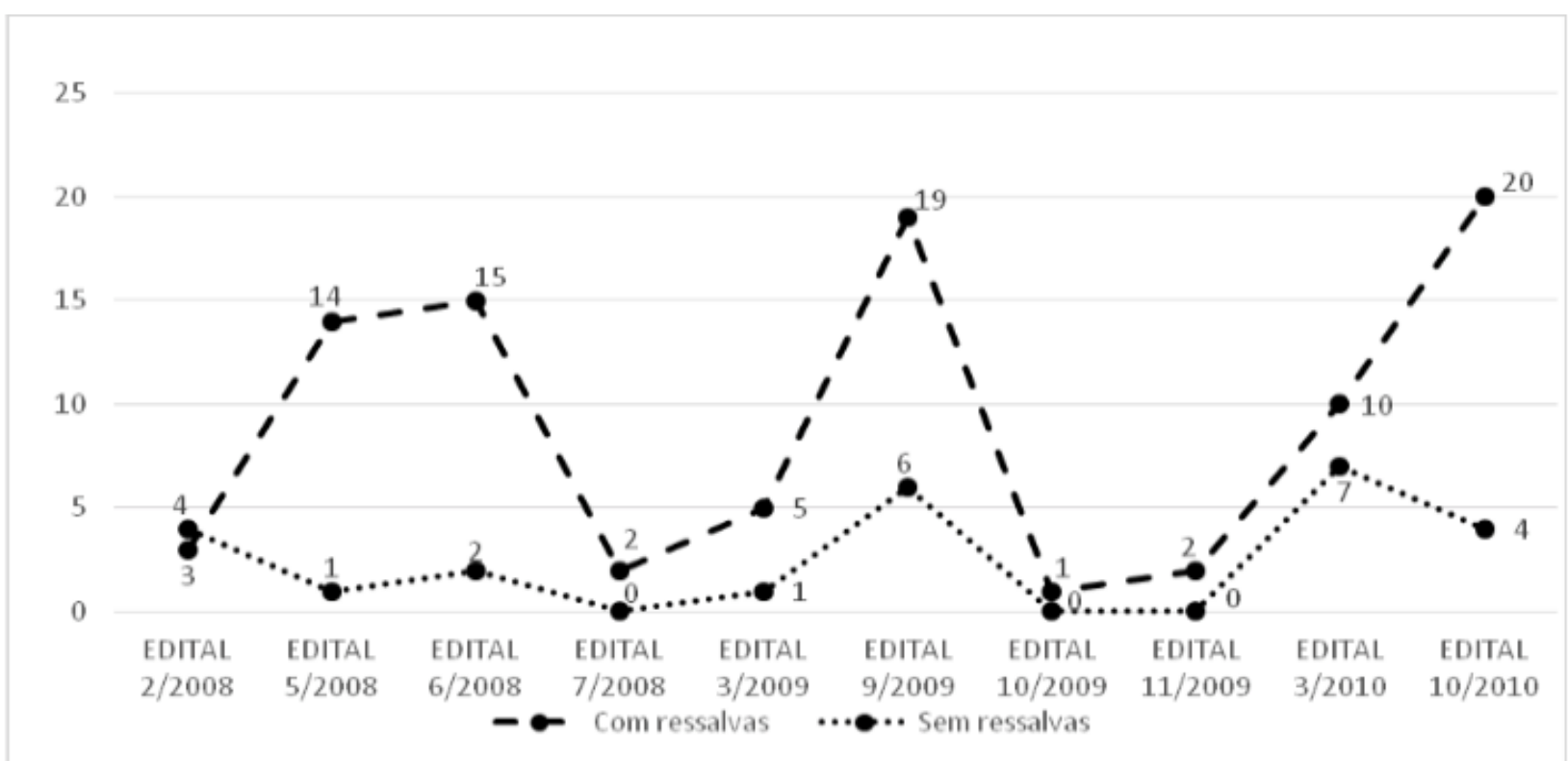

Figura 1. Processos analisados por edital com proporção de ressalvas

Fonte: Dados da pesquisa (2017)

A análise do gráfico ressalta que, dos 116 relatórios, somente 25 estavam em conformidade com os respectivos editais, o que corresponde a $21,55 \%$ do total. Esse resultado é relevante, uma vez que a tendência é que exista sempre uma maioria absoluta de projetos de pesquisas com ressalvas em sua execução orçamentária.

Além disso, ao observar o referido gráfico identifica-se uma tendência de aumento na quantidade de ressalvas, haja vista que se for analisado o início da série histórica, a proporção de editais com ressalvas pelo total de editais é de $57 \%$, ou seja, do total de projetos financiados pelo edital 2/2008 (7), 4 apresentaram algum tipo de ressalva. Esse número eleva-se no edital 5/2008 para 93\% (14/15) e encerra a série com 83\% (20/24) quando analisado o edital 10/2010.

Em que pese a não linearidade da série histórica quando se refere à quantidade de projetos financiados entre 2008 e 2010 e sua proporção entre aqueles que apresentaram ressalvas e os que não apresentaram, a quantidade de relatórios com algum item que justifique a sua não aprovação ou aprovação parcial, é relevante, sinalizando que ações de orientação devem ser realizadas a fim de minimizar ou até mesmo mitigar tais incorreções.

Para isso, em uma primeira análise, destaca-se que o monitoramento da execução do orçamento financeiro dos projetos de pesquisa seja uma etapa necessária para que tais ressalvas diminuam. Porém, no atual estágio identificado internamente na FAPDF, ainda é premente que ocorra a implantação de controles internos que sinalizem aspetos básicos, tais como: 1) editais publicados; 2) quantidade de projetos e seu detalhamento, incluindo dados dos pesquisadores e prazo para entrega dos relatórios de prestação de contas; e 3) cronograma financeiro de cada projeto. Os itens apontados foram tabulados pela pesquisa por meio de levantamento próprio. 
Portanto, conforme Lima e Castro (2006) e Castro (2008) afirmam, a contribuição dos controles internos para promoverem maior confiabilidade das informações, neste caso, da execução financeira dos projetos de pesquisa, somente ocorrerá quando estes forem efetivos, que por sua vez, irá acontecer à medida que os colaboradores compreenderem cada qual o seu papel no fluxo da rotina dos processos internos bem como no sistema de controle.

Para tanto, tais procedimentos somente ocorrerão ou exercerão de fato o papel de assegurar que as ações ou tomadas de decisão estejam convergentes com os objetivos estratégicos da organização, à medida que a alta administração patrocinar e fizer cumprir o propósito para o qual o sistema de controle interno deve ser implantado (Schwartz, Dunfee, \& Kline, 2005; COSO, 2013). Ao passo que isso não ocorre, as ações são realizadas de forma reativa, ou seja, à medida que existentem cobranças externas, especialmente advindas do órgão fiscalizador, o que segundo Capovilla e Gonçalves (2018, p. 179) acarreta em um ambiente caracterizado pela "falta de aderência e de comprometimento dos empregados para construir um ambiente de controle que vise cumprir os objetivos organizacionais".

Como consequência de um ambiente caracterizado pela ausência de controles, há maior risco quanto aos seguintes aspectos: reputacional, de comprometimento quanto ao comportamento esperado sob o ponto de vista ético dos processos, da existência de pessoal sem as competências necessárias para o exercício de suas atribuições, de alocação de recursos divergentes com os objetivos estratégicos da entidade (Schwartz, Dunfee, \& Kline, 2005; Johnstone, Gramling, \& Rittenberg, 2013).

Adicionalmente, com objetivo de levantar os aspectos que levaram tais relatórios a obter ressalvas, foi elaborada a Tabela 2, que evidencia cada uma das ressalvas segregadas por cada um dos editais, distribuídos nos 116 relatórios de prestação de contas analisados. Para cada quesito ao fim da linha foi levantado o somatório da quantidade de ressalvas em todos editais.

Tabela 2

Ressalvas identificadas nos relatórios de prestação de contas por edital

\begin{tabular}{|c|c|c|c|c|c|c|c|c|c|c|c|}
\hline \multirow{5}{*}{ Observações } & \multicolumn{10}{|c|}{ Editais } & \multirow{4}{*}{$\begin{array}{l}\mathbf{T} \\
\mathbf{O} \\
\mathbf{T} \\
\mathbf{A} \\
\mathbf{L}\end{array}$} \\
\hline & \multicolumn{5}{|c|}{2008} & \multicolumn{3}{|c|}{2009} & \multicolumn{2}{|c|}{2010} & \\
\hline & 2 & 5 & 6 & 7 & 8 & 9 & 10 & 11 & 3 & 10 & \\
\hline & \multicolumn{10}{|c|}{ Relatórios por edital } & \\
\hline & 7 & 15 & 17 & 2 & 6 & 25 & 1 & 2 & 17 & 24 & 116 \\
\hline $\begin{array}{l}\text { 1) Utilizou rendimentos } \\
\text { financeiros sem autorização }\end{array}$ & 0 & 9 & 3 & 2 & 3 & 12 & 0 & 2 & 4 & 5 & 40 \\
\hline $\begin{array}{l}\text { Não apresentou os três } \\
\text { orçamentos do item }\end{array}$ & 1 & 2 & 5 & 0 & 2 & 5 & 0 & 0 & 4 & 8 & 27 \\
\hline $\begin{array}{l}\text { 3) Não apresentou todos } \\
\text { extratos bancários }\end{array}$ & 0 & 4 & 5 & 1 & 1 & 5 & 1 & 1 & 2 & 3 & 23 \\
\hline $\begin{array}{l}\text { 4) Não utilizou cheque } \\
\text { nominativo para pagamento } \\
\text { de despesa }\end{array}$ & 1 & 0 & 5 & 0 & 3 & 2 & 0 & 0 & 1 & 4 & 16 \\
\hline $\begin{array}{l}\text { 5) Houve remanejamento de } \\
\text { recursos destinados de } \\
\text { rubrica para rubrica }\end{array}$ & 0 & 1 & 4 & 0 & 3 & 2 & 0 & 0 & 1 & 4 & 15 \\
\hline $\begin{array}{l}\text { 6) Adquiriu item que não } \\
\text { estava previsto no } \\
\text { orçamento }\end{array}$ & 0 & 5 & 4 & 0 & 1 & 2 & 0 & 0 & 0 & 1 & 13 \\
\hline $\begin{array}{l}\text { 7) Não apresentou nota fiscal } \\
\text { de item }\end{array}$ & 0 & 1 & 3 & 0 & 0 & 1 & 0 & 0 & 3 & 3 & 11 \\
\hline
\end{tabular}




\begin{tabular}{l|c|c|c|c|c|c|c|c|c|c|c}
$\begin{array}{l}\text { 8) Houve remanejamento de } \\
\text { recursos destinados, item } \\
\text { para item, acima de 20\% }\end{array}$ & 0 & 1 & 1 & 1 & 0 & 1 & 0 & 0 & 1 & 2 & $\mathbf{7}$ \\
\hline $\begin{array}{l}\text { 9) Gasto com diária acima } \\
\text { do valor permitido }\end{array}$ & 0 & 3 & 0 & 0 & 0 & 0 & 0 & 0 & 0 & 0 & $\mathbf{3}$ \\
\hline $\begin{array}{l}\text { 10) Não devolveu valor } \\
\text { residual }\end{array}$ & 1 & 1 & 0 & 0 & 0 & 0 & 0 & 0 & 0 & 0 & $\mathbf{2}$ \\
\hline
\end{tabular}

Fonte: Dados da pesquisa (2017)

De acordo com a Tabela 2, identifica-se um total de 157 ressalvas, soma da quantidade de ressalva por quesito, para os 116 relatórios analisados, assim sendo, nota-se que as divergências identificadas, considerando-se a análise por projeto/edital e em ordem decrescente de ocorrência total, em sua maioria foram observadas em mais de um relatório financeiro. Ressalta-se que, em média, nenhum dos editais apresentou relatórios em total conformidade com os procedimentos necessários para execução orçamentária.

Ao explorar de forma analítica cada uma das ressalvas, o primeiro item com maior quantidade de ressalvas (utilizou rendimentos financeiros sem autorização) tem por objetivo identificar se os rendimentos da aplicação financeira dos recursos depositados ao projeto foram devolvidos ou se utilizados mediante autorização prévia. Segundo a Instrução Normativa 01 (2005), art. $7^{\circ}$, inciso XIV, os rendimentos de aplicação no mercado financeiro devem ser recolhidos à conta da concedente, e somente devem ser utilizados mediante autorização prévia junto à FAPDF. Nesse item foram identificados quarenta projetos $(34,5 \%)$ que se utilizaram dos recursos oriundos dos rendimentos de aplicações financeiras, contudo, sem a autorização pelo órgão de fomento. Esse tipo de ocorrência decorre principalmente pelo desconhecimento do pesquisador que está realizando a execução financeira, uma vez que ao identificar a existência de saldo financeiro no projeto executa-o por compreender que o recurso se encontra disponível para a realização das atividades de pesquisa.

Sob a ótica de um sistema de controles internos, evitar o uso indevido de recursos financeiros (no caso sem que haja uma autorização prévia) é um dos aspectos mais básicos que devem existir (sobretudo em se tratando de entidades que financiam projetos de pesquisa), uma vez que a entidade que controla os recursos, deve ter condições de monitorar o andamento da execução orçamentária a ponto de impedir que recursos além do limite aprovado no projeto de pesquisa seja utilizado sem o seu consentimento (COSO, 2013; GAO, 2014).

$\mathrm{O}$ segundo item de maior ocorrência de ressalvas (não apresentou os três orçamentos do item) analisa se para a aquisição de bens tipificados como de capital, foram apresentados, no mínimo, três orçamentos conforme a Lei $\mathrm{n}^{\circ}$ 8.666/1993, art. $15^{\circ}$. Foram identificados 27 projetos $(23,3 \%)$ que executaram o orçamento de capital, contudo, sem a apresentação dos respectivos orçamentos. Apesar desse resultado, os pesquisadores ao serem questionados especificamente sobre esse aspecto, $92 \%$ afirmaram que cumpriram tal dispositivo, enquanto, aproximadamente $8 \%$ afirmam que raramente ou nunca realizaram.

Em que pese os respondentes representarem uma amostra do total dos projetos analisados, identifica-se uma discrepância entre o que se apurou por meio dos relatórios de prestação de contas e o que os pesquisadores relatam enquanto procedimento realizado para execução do orçamento de capital.

Talvez os resultados apresentados para os itens 1 e 2 possam ser parcialmente explicados pelo que declaram os pesquisadores quando questionados acerca da dificuldade de entendimento às regras para a prestação de contas, bem como a clareza em que tais regras são apresentadas. Assim sendo, apesar de observarem com frequência os itens contidos no orçamento de seus projetos, na visão dos pesquisadores, $79 \%$ afirmam que apresentam dificuldade no entendimento às regras para a prestação de contas, enquanto $77 \%$ afirmam dificuldade em relação à clareza em que as regras para execução financeira dos projetos são apresentadas. 
Ainda a esse respeito, um dos pesquisadores sugere que seja realizada "capacitação dos contemplados como item obrigatório para liberação do recurso e para cumprir a prestação de contas" (Pesquisador B), bem como um manual que possua maior clareza para contribuir na identificação dos itens caracterizados como despesa de capital ou de custeio. A esse respeito temse a percepção do pesquisador a seguir, que sugere:

Elaborar um folder explicativo com o que pode ou não fazer. Mas, que seja em linguagem que qualquer pesquisador possa entender. Não adianta dizer pode capital ou pode custeio... Tem que dizer o que é capital e o que é custeio. Tipo um manual de instrução de um equipamento. (Pesquisador D)

Um exemplo dessa ausência de clareza no que tange aos procedimentos para a execução do cronograma financeiro é evidenciado pelas ressalvas dos itens 3 (não apresentou todos extratos bancários) e 4 (não utilizou cheque nominativo para pagamento de despesa), que tratam de aspectos de fácil realização, e juntos representam 33,6\% do total das ressalvas.

Apesar de haver previsão legal para que tais documentos sejam assim apresentados no relatório de prestação de contas (Instrução Normativa 01, 2005, art. 26, inciso VII - em relação à apresentação do extrato da conta bancária; e emissão de cheque nominativo, conforme Termo de Outorga e Aceitação de cada projeto) verifica-se que tais aspectos possivelmente sejam de desconhecimento dos pesquisadores justamente pelo aspecto ora apontado.

De modo geral, as ressalvas se repetem entre os relatórios analisados, e verifica-se que a maioria dos editais apresentou expressivo número de ressalvas (mais de $20 \%$ dos relatórios por edital) em dissonância com a legislação vigente nos três primeiros tópicos, relacionados com os quesitos 1, 2 e 3, respectivamente. Em relação ao total de relatórios, verifica-se que as seis primeiras observações foram encontradas em pelo menos $10 \%$ dos relatórios.

O interessante é que com o passar dos anos, verifica-se que os erros se repetem, o que pode ser um sinalizador para a existência de procedimentos considerados adequados por parte dos pesquisadores ou simplesmente por desconhecimento, o que sinaliza a necessidade de uma maior aproximação entre o Órgão de Fomento e os pesquisadores. Apesar disso, os itens de 1 a 4 podem ser considerados menos relevantes se comparados aos itens de 5 a 10 que, embora com menor frequência, representam aspectos de maior atenção no momento da análise dos relatórios e alcançaram em conjunto aproximadamente $44 \%$ do total de ressalvas.

$\mathrm{O}$ item 5 (houve remanejamento de recursos destinados de rubrica para rubrica) tem por objetivo analisar se houve remanejamento de recursos destinados de custeio à capital ou viceversa. De acordo com a Lei $\mathrm{n}^{\circ} 4.320 / 1964$, art. $11^{\circ}$, os recursos provenientes de uma rubrica só podem ser usados em despesas de mesma rubrica. Tal situação foi identificada em aproximadamente $13 \%$ dos relatórios analisados.

Assim como ocorre com o uso de recursos financeiros além do aprovado no projeto de pesquisa (uso de rendimentos de aplicação financeira), o uso de recursos em diferentes rubricas, no caso de custeio para capital ou vice-versa, decorre inicialmente de uma falta de compreensão básica quanto ao uso dos recursos públicos, haja vista esta ser uma regra básica sob a ótica orçamentária. Contudo, em que pese esse aspecto, controles direcionados a esse quesito, e sobretudo, ações de orientação que demandam baixo custo se comparado às implicações advindas dessa prática, poderão mitigar substancialmente a ocorrência dessa incongruência.

Já o item 6 (adquiriu item que não estava previsto no orçamento) tem por objetivo identificar que houve o cumprimento integral ao cronograma financeiro aprovado inicialmente ou a posteriori por meio de autorização prévia, uma vez que a Instrução Normativa 01 (2005), em seu artigo $8^{\circ}$, veda a utilização de recursos em finalidade diversa da preestabelecida, ainda que em caráter emergencial. Nesse item foram identificados treze projetos $(11,2 \%)$ com a utilização de recursos de forma divergente ao que fora inicialmente proposto em seu cronograma financeiro. 
Sobre esse aspecto, cerca de $89 \%$ dos pesquisadores mencionam que ao realizar a execução do cronograma financeiro, sempre ou muitas vezes, observavam o orçamento aprovado em seu projeto de pesquisa, o que até certo ponto vai ao encontro com os dados obtidos por meio da análise dos relatórios de prestação de contas. Contudo, observando-se os demais respondentes, aproximadamente $11 \%$ raramente ou nunca analisavam o cronograma financeiro aprovado no projeto para realização da execução orçamentária. A verificação dos itens financiados pelo edital, bem como aqueles aprovados no projeto é procedimento básico e necessário para a execução dos recursos financeiros destinados, haja vista a característica da execução dos recursos públicos (recursos destinados às rubricas específicas).

Esse tipo de comportamento também acaba por explicar as ressalvas identificadas nos itens 8 (houve remanejamento de recurso destinado item para item, acima de 20\%) e 9 (gasto com diária acima do valor permitido), uma vez que, para estes casos, somente a não observância da proposta financeira aprovada é que justifica o não cumprimento de tais itens.

Apesar de não terem conhecimento dos resultados ora apresentados, de um modo geral, os pesquisadores esperam que os procedimentos adotados pela FAPDF se aproximem do que é realizado em um outro órgão de fomento $(\mathrm{CNPq})$ no qual permite o remanejamento de recursos em uma mesma rubrica, sem prévia autorização.

Adotar modelos semelhante ao do CNPq, que a maioria dos pesquisadores já conhecem. (Pesquisador E)

A aquisição de itens de material de consumos não deveriam ser especificados no início de projeto. Essa determinação não traz lisura nem melhor gasto pelo pesquisador. Exemplo de uma situação comum - faço um projeto, coloco um material de consumo. A implementação e início das atividades demoram em média, se tudo correr bem, um ano. Quando inicio, as atividades novas técnicas podem surgir, novas experiências na área, além de outros projetos estarem em andamento e o pesquisador poder adquirir determinado material com outras fontes. Assim, material de consumo deve ser extremamente flexível. (Pesquisador C, destaque nosso)

Por outro lado, no item 7 (não apresentou nota fiscal de item), que ocorreu em 9,4\% das ressalvas, apesar de se tratar de um item importante, observa-se que tal ocorrência se deve em virtude do desconhecimento quanto ao que a legislação define como comprovante hábil e o que foi apresentado como documento comprobatório pelo pesquisador (por exemplo: nota fiscal para aquisição de bens e serviços de pessoas jurídicas e recibos para as pessoas físicas).

Os resultados relatados até aqui demonstram falta de conhecimento acerca do manuseio dos recursos públicos indo de encontro ao que se espera de um processo que esteja calcado no conceito de accountability, uma vez que está diretamente relacionado à responsabilização daquele que maneja o recurso público. Esse ambiente rebate a ideia do uso eficiente desses recursos e não há de certo modo a preocupação com o cumprimento da norma legal, como diversos autores (Campos, 1990; Carneiro, 2004; Afonso, 2009; Pinho \& Sacramento, 2009); já afirmaram em seus trabalhos. Ao confrontar os dados do questionário com os dados nos relatórios nota-se divergências evidentes. Verifica-se que os pesquisadores têm noção das normativas sobre uso de recursos públicos ao dizerem praticar ações recomendáveis, porém, de modo superficial e atrelada mais a noções popularmente difundidas do que as exigências da lei, ressaltando-se que em relação aos recursos públicos, a utilização deve estar em total congruência com as normas legais.

Acredita-se que a maior parte das ressalvas identificadas decorre, em parte pelo desconhecimento do pesquisador acerca de como proceder, haja vista que são procedimentos que não demandam maior complexidade, e que por sua vez, evidencia a necessidade de melhorias na comunicação entre as partes interessadas (uma das dimensões do COSO quanto aos controles internos), no caso a FAPDF e os pesquisadores. 
Considerando o ambiente de controle identificado, bem como a repetição das ressalvas nos relatórios de prestação de contas, depreende-se que o controle interno da FAPDF não conseguiu atingir seus objetivos operacionais e estratégicos. Inicialmente porque não monitorou incoerências relevantes e cumulativas ocorridas nos relatórios financeiros dos projetos de pesquisa, e por outro lado, ao ocorrer tal fato, não subsidia por meio de respostas tempestivas e relevantes a administração no sentido de corrigir tais ocorrências. Os resultados ora identificados vão de encontro ao que se espera do papel a ser exercido pelas estruturas de controle e auditoria internos na avaliação dos processos organizacionais para que a organização atinja seus objetivos (Fontenelle \& Brito, 2013; Silva, 2009; Vieira \& Freitas, 2015).

Ao analisar os procedimentos de forma individualizada, é possível afirmar que são relativamente simples, contudo, considerando-se todo o processo de prestação de contas no atual contexto, é visível a excessiva burocracia no processo de utilização de recursos, não sendo com isso um procedimento transparente, a exemplo, para obtenção de autorização de utilização de rendimentos ou mudanças no cronograma financeiro. A esse respeito cabe registrar a percepção a seguir.

O processo é muito amarrado e burocrático. O pesquisador tem que pensar a priori em todos os itens que terá que comprar. Isso é impossível em pesquisa experimental, particularmente no que se refere a despesas de custeio. Deveria haver maior flexibilidade nos gastos (obedecidas os limites das rubricas) para os pesquisadores, ao invés de terse que pedir autorização à $F A P$ a cada aquisição que eventualmente não constou do orçamento original. (Pesquisador A, grifo nosso)

Nesta perspectiva, observa-se que todo o processo relacionado à prestação de contas de projetos financiados nesta organização não observa a ementa da nova gestão pública no Brasil, especialmente no que diz respeito à produção de indicadores e controle de resultados (Hood, 1991; Pollitt, 2002). Kelly (2000) ainda coloca que no âmbito da Administração Pública é preciso remodelar processos para evitar falhas de gestão, especialmente porque a atenção dada aos objetivos estratégicos, à performance e à avaliação acrescem os ganhos de percepção pública acerca do desempenho da instituição. Destaca ainda que a simplificação dos processos e procedimentos administrativos melhoram os níveis de eficácia e eficiência organizacional.

Desse modo, a melhoria no processo de prestação de contas só será possível com a revisão, simplificação dos processos e produção de uma comunicação eficiente entre os colaboradores e pesquisadores. Esta comunicação está nos meios de interlocução, no manual de prestação de contas e o desenvolvimento de um sistema de prestação de contas. Isso poderá estimular o desenho de um sistema de controle que compreenderá o contexto estratégico e social da organização (Salas \& Gomes, 1999).

\section{CONSIDERAÇÕES FINAIS}

A responsabilidade da Fundação de Apoio à Pesquisa do Distrito Federal pelo acompanhamento e execução dos processos visa o desenvolvimento, o crescimento de diversos projetos e trabalhos que agregarão valor ao campo científico. Tais pesquisas são de extrema importância, pois a partir delas é possível o desenvolvimento de áreas importantes, como exemplo, a tecnologia e questões necessárias para o crescimento do País, levando em consideração que quanto mais crescem os níveis das pesquisas, mais o Distrito Federal tende a ganhar com os seus retornos, e de forma ampliada, o Brasil também.

Neste artigo buscou-se a compreensão do processo de prestação de contas de projetos de pesquisa, especificamente em que medida o sistema de controles internos da FAPDF contribui no acompanhamento e análise da conformidade da alocação de recursos financeiros dos projetos de pesquisas em que financia. 
Tendo em vista a responsabilidade que envolve a execução e prestação de contas de recursos públicos, é preciso que haja coerência em seus procedimentos internos e nas realizações de todo o processo de análise dos relatórios. Não é uma tarefa simples, e, portanto, constatou-se a premente necessidade de melhorar os processos organizacionais, especialmente a superação da excessiva burocracia. Esta se não superada, implica na perda de objetividade e distanciamento dos princípios da nova gestão pública. Tal distanciamento do propósito tende a ser decorrente da ausência de princípios que norteiem o sistema de controles internos que permitem apontar recorrentes falhas ao longo da execução orçamentária dos respectivos projetos, o que por sua vez contribui para a persistência dessas falhas.

A constatação de falhas na utilização correta dos recursos públicos, a baixa qualidade na comunicação entre colaboradores e pesquisadores, bem como a ausência de controle no processo de prestação de contas podem levar esta fundação de apoio a perder o comando dos recursos destinados ao financiamento de projetos de pesquisa científica e tecnológica. Controles esses que devem ser interligados (Schmidt \& Arima, 2006) e que englobe todas as funções administrativas, conectando de forma coerente a estrutura da instituição ao planejamento, execução e controle, haja vista que trata de uma organização de natureza pública.

A adoção de procedimentos internos a exemplo de orientações descritivas, exemplificativas e itemizadas, pode contribuir para diminuir as dúvidas existentes dos pesquisadores no momento da execução dos gastos em seus projetos de pesquisas. Além disso, a busca pela redução dos procedimentos considerados burocráticos também poderia contribuir para uma melhor dinâmica da execução orçamentária e consequentemente da sua prestação de contas.

Por fim, a pesquisa realizada poderá inspirar o desenvolvimento de soluções que provoquem ou despertem a mudança na organização internamente e consequentemente no seu ambiente externo, tendo em vista a sua participação valorosa no desenvolvimento de pesquisas no Distrito Federal. Sugere-se que pesquisas desta natureza sejam desenvolvidas em outras agências de fomento nas diversas unidades da federação, pois os indicativos aqui demonstrados poderão ser identificados de forma similar, haja vista o funcionamento das organizações desta natureza.

\section{AGRADECIMENTOS}

Os pesquisadores agradecem a FAP/DF pelo financiamento da pesquisa, bem como a contribuição de seus colaboradores que foram fundamentais para o desenvolvimento da pesquisa. Pesquisa financiada pelo Edital FAP/DF 03/2015.

\section{REFERÊNCIAS}

Afonso, A. J. (2009). Políticas avaliativas e accountability em educação: subsídios para um debate Iberoamericano. Sísifo: revista de Ciências da Educação, (3), 57-70.

Bergamini, S., Jr. (2005). Controles internos como um instrumento de governança corporativa. Revista do BNDES, 12(24), 149-187.

Bresser-Pereira, L. C. (2000). A Reforma Gerencial do Estado de 1995”. Revista de Administração Pública, 34 (4).

Bresser-Pereira, L. C. (1997). A Reforma do Estado dos Anos 90: Lógica e mecanismos de controle. (Cadernos MARE da reforma do estado). Brasília: Ministério da Administração Federal e Reforma do Estado. 
Campos, A. M. (1990). Accountability: quando poderemos traduzi-la para o português? Revista de Administração Pública, 24(2), 30-50.

Capovilla, R. A. (2016). Análise das Estruturas de Controle Interno de Organizações Governamentais por Meio de Modelo de Maturidade. Dissertação de mestrado, Programa Multi-institucional e Inter-Regional de Pós-Graduação em Ciências Contábeis da Universidade de Brasília, da Universidade Federal da Paraíba e da Universidade Federal do Rio Grande do Norte, Brasília, Brasil.

Capovilla, R. C., Gonçalves, R. de S., Dantas, J. A., \& Oliveira, A. B. S. (2018). Modelo de maturidade de estruturas de controle interno em organizações governamentais. Advances in Scientific \& Applied Accounting, 11(2).

Capovilla, R. C., \& Gonçalves, R. de S. (2018). Avaliação do Ambiente de Controle Interno por Meio de Modelo de Maturidade em Organizações Governamentais. Contextus - Revista Contemporânea de Economia e Gestão, 16, (2).

Carneiro, C. B. L. (2004). Governança e accountability: algumas notas introdutórias. Belo Horizonte: Fundação João Pinheiro.

Castro, D. P. (2008). Auditoria e controle interno na administração pública. São Paulo: Atlas.

Committee on the Financial Aspects of Corporate Governance (1992). The Financial Aspects of Corporate Governance. Londres: GEE.

COSO - Committee of Sponsoring Organizations of the Treadway Commission (2013). Internal Control - Integrated Framework: Framework and Appendices.

Constituição da República Federativa do Brasil de 1988 (1988). Brasília. Recuperado em 6 junho, 2017, de http://www.planalto.gov.br/ccivil03/Constituicao/Constituicao.htm

Decreto distritral $n^{\circ} 27.958$, de 16 de maio de 2007. (2007). Aprova o Estatuto Social da Fundação de Apoio à Pesquisa do Distrito Federal e dá outras providências. Brasília. Recuperado em $6 \quad$ junho, 2017, http://www.sinj.df.gov.br/sinj/Norma/55052/Decreto_27958_16_05_2007.pdf

Denhardt, R. B. (2012). Teorias da Administração Pública (6ª ed.). São Paulo: Cengage Learning.

FAPDF - Fundação de Apoio à Pesquisa do Distrito Federal (2017). Sobre a Fundação de Apoio à Pesquisa do Distrito Federal. Recuperado em: 8 junho, 2017, de http://www.fap.df.gov.br/sobre-a-fundacao/a-fundacao.html

Ferreira, R. J. (2002). Auditoria (2a ed.). Rio de Janeiro: Ferreira.

Fontenelle, R., \& Brito, C. (2013). Auditoria privada e governamental (2a ed.). Rio de Janeiro: Elsevier.

GAO - United States General Accountability Office (2001). Internal Control Management and Evaluation Tool. 
GAO - United States General Accounting Office (2014). Standards for Internal Control in the Federal Government (The Green Book).

Gonçalves, A. de O., Gonçalves, R. de S., \& Tavares, A. de Lima (2011). O olhar dos conselheiros de saúde sobre os relatórios de prestação de contas no município de Natal (Rio Grande do Norte), Brasil. Saúde e Sociedade, 20(3), 659-672.

Hair, F. Jr., Rabin, B., Money, A. H., \& Samouel, P. (2005). Fundamentos de métodos de pesquisa em administração. Porto Alegre: Bookman.

Hendriksen, E. S., \& Van Breda, M. F. (1999). Teoria da contabilidade. (tradução de Antonio Zoratto Sanvicente). São Paulo: Atlas.

Hood, C. (1991). A Public Management For All Seasons? Public Administration, 69(1), 3-19.

Instrução Normativa 01, de 22 de dezembro de 2005 (2005). Disciplina a celebração, o emprego de recursos e a correspondente prestação de contas de convênios, acordos, ajustes e outros instrumentos congêneres, pelos órgãos e entidades da Administração Direta e Indireta do Distrito Federal tendo como objetivo a execução de programa, projeto ou atividade de interesse recíproco, e dá outras providências. Brasília. Recuperado em 6 junho, 2017, de http://www.sinj.df.gov.br/sinj/Norma/48050/Instru_o_Normativa_1_22_12_2005.html

IFAC - International Federation of Accountants (2001). Governance in the Public Sector: A Governing Body Perspective. Study 13. Retrieved December 20, 2018 from http://www.ifac.org

International Organisation of Supreme Audit Institutions (2004). GOV 9100. Guidelines for Internal Controls Standards for the Public Sector. Recuperado em 1 janeiro, 2015, de http://www.issai.org/media/13329/intosai_gov_9100_e.pdf.

Johnstone, K., Gramling, A., \& Rittenberg, L. E. (2013). Auditing: a risk-based approach to conducting a quality audit. Cengage learning.

Kelly, M. (2000). Public Service Modernisation in Ireland: an examination of the factors affecting success in reform. In I. Corte-Real, K. Nomden, M. Kelly \& F. Petitevill. Administrations in Transition: Modernisation of Public Administration in Four Countries: Portugal, the Netherlands, Ireland and France. Maastricht: European Institute of Public Administration.

Lei distrital $n^{\circ}$ 347, de 04 de novembro de 1992 (1992). Autoriza constituir a Fundação de Apoio à Pesquisa do Distrito Federal e dá outras providências. Brasília. Recuperado em 6 junho, 2017, de http://www.sinj.df.gov.br/sinj/Norma/23118/Lei_347_04_11_1992.html

Lei $n^{\circ} 4.320$, de 17 de março de 1964 (1964). Estatui Normas Gerais de Direito Financeiro para elaboração e contrôle dos orçamentos e balanços da União, dos Estados, dos Municípios e do Distrito Federal. Brasília. Recuperado em 6 junho, 2017, de http://www.planalto.gov.br/ccivil_03/leis/L4320.htm

Lei $n^{\circ}$ 8.666, de 21 de junho de 1993 (1993). Regulamenta o art. 37, inciso XXI, da Constituição Federal, institui normas para licitações e contratos da Administração Pública e dá outras providências. Brasília. Recuperado em 6 junho, 2017, de http://www.planalto.gov.br/ccivil_03/Leis/L8666cons.htm 
Lei orgânica do distrito federal (1993). Brasília. Recuperado em 6 junho, 2017, de http://www.sinj.df.gov.br/sinj/Norma/66634/Lei_Org_nica_08_06_1993.html

Lima, D. V., \& Castro, R. G. (2006). Contabilidade pública: integrando União, estados e municípios (Siafi e Siafem). São Paulo: Atlas.

Lopes, F. C., \& Freire, G. M. (2010). Governo Eletrônico e Accountability: Avaliação da Publicização das Contas Públicas dos Estados Brasileiros. Anais do Encontro Nacional do CONPEDI, Fortaleza, 19.

O`Donnell, G. (1998). Accountability horizontal e novas poliarquias. Lua Nova: Revista de Cultura e Política, (44), 27-54.

Oliveira, R. S. de, Hochman, B., Nahas, F. X., \& Ferreira, L. M. (2005). Fomento à publicação científica e proteção do conhecimento científico. Acta Cirurgica Brasileira, 20(Suppl. 2), 35-39.

Pinho, J. A. G de, \& Sacramento, A. R. S. (2009). Accountability: já podemos traduzi-la para o português? Revista de Administração Pública, 43(6), 1343-1368.

Pollitt, C. (2002). The new public management in international perspective. In K. McLaughlin, S. P. Osborne and E. Ferlie. New Public Management: Current Trends and Future Prospects. London: Routledge, 274.

Resolução CFC $n^{o}$. 1.135 de 2008 (2008). Aprova a NBC T 16.8 - Controle Interno. NBC T 16 Normas Brasileiras de Contabilidade Aplicadas ao Setor Público. Recuperado em 6 junho, 2017, de http://www1.cfc.org.br/sisweb/SRE/docs/RES_1135.pdf

Resolução normativa $n^{\circ} 01$, de 16 de agosto de 2013 (2013). Estabelece Valores de Diárias no País e no Exterior. Brasília. Recuperado em 6 junho, 2017, de http://www.sinj.df.gov.br/sinj/Norma/75865/Resolu_o_Normativa_1_16_08_2013.html

Rocha, A. C. (2011). Accountability na Administração Pública: Modelos teóricos e abordagens. Contabilidade, Gestão e Governança, 14(2), 82-97.

Salas, J. M., \& Gomes, J. S. (1999). Controle de gestão: uma abordagem contextual e organizacional . São Paulo: Atlas.

Schmidt, P., \& Arima, J. L. (2006). Fundamentos de auditoria de sistemas. São Paulo: Atlas.

Scott, D. R. (1941). The basis for accounting principles. Accounting Review, 341-349.

Silva, M. M. (2009). Curso de Auditoria Governamental. São Paulo: Atlas.

Schwartz, M. S., Dunfee, T. W., \& Kline, M. J. (2005). Tone at the top: An ethics code for directors? Journal of Business Ethics, 58(1-3), 79.

Vieira, E. T., \& Freitas, J. C. (2015). O reflexo do controle interno e do COSO para a auditoria e a governaça corporativa a partir de uma pesquisa exploratória. Revista científica hermes (14), 155-175. 
Zahra, S. A. (2014). Public and Corporate Governance and Young Global Entrepreneurial Firms. Corporate Governance: An International Review, 22(2), 77-83. 